\title{
Consumer Behaviour Analysis in Online Music Purchases in Indonesia by Implementing 7P's Marketing Strategy Using Quality Function Deployment (QFD)
}

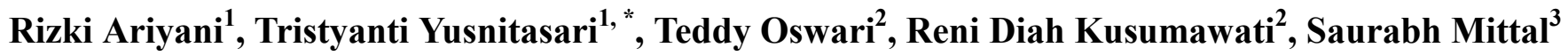 \\ ${ }^{1}$ Faculty of Computer Science, Gunadarma University, Depok, Indonesia \\ ${ }^{2}$ Faculty of Economics, Gunadarma University, Depok, Indonesia \\ ${ }^{3}$ Faculty of Computer Science, Asia Pacific Institute of Management, New Delhi, India
}

\section{Email address:}

rizkiariyani25@yahoo.com (R. Ariyani),tyusnita@staff.gunadarma.ac.id (T. Yusniasari), toswari@staff.gunadarma.ac.id (T. Oswari), reni_dk@staff.gunadarma.ac.id (R. D. Kusumawati), sau275@gmail.com (S. Mittal)

${ }^{*}$ Corresponding author

\section{To cite this article:}

Rizki Ariyani, Tristyanti Yusnitasari, Teddy Oswari, Reni Diah Kusumawati, Saurabh Mittal. Consumer Behaviour Analysis in Online Music Purchases in Indonesia by Implementing 7P's Marketing Strategy Using Quality Function Deployment (QFD). American Journal of Engineering and Technology Management. Vol. 4, No. 3, 2019, pp. 57-65. doi: 10.11648/j.ajetm.20190403.11

Received: January 31, 2019; Accepted: May 21, 2019; Published: September 27, 2019

\begin{abstract}
Music is the expression of one's feelings which are expressed in beautiful tones and poems. Music can be packaged in the form of cassette or Compact Disc (CD), on this millennial era, music can be enjoyed from music sites, as well as in smartphone applications with various musical genres. Music is easy to access now, where people can enjoy music anywhere and anytime through music sites. To build a system for purchasing music online, this study is aim to analyze consumer behavior in purchasing music online in Indonesia by implementing 7P's Marketing Strategy and Quality Function Deployment (QFD). Questionnaire is used to get data from respondents and data obtained from respondents will be processed using the Application of Quality Functions. Data from respondents are to identify consumer needs and for technical requirements. The research methodology begins with gathering user needs and analyze data using QFD. The results of analysts on House of Quality have 6 elements that are prioritized for the development of system that will be built on purchase music online.
\end{abstract}

Keywords: Consumer Behavior, Online Music, 7P's Marketing Strategy, QFD

\section{Introduction}

In this millennium, the challenges of business in the future will be even more difficult, due to advances in technology and science. The development of business opportunities can increase market share competition in all industrial sectors, because every company wants to increase its market share. Depends on internal and external factors that are in accordance with the product being marketed.

Relevant to the statement above, the music industry in Indonesia continues decline in sales. The large numbers of music stores in Jakarta that are closed is proof that CD is no longer ogled by the public, so the company no longer strives to increase sales of music products in $\mathrm{CD}$, cassette, or Ring Back Tones (RBT), but company offering other types of music product such as online music. The decrease of music sales is causing by the piracy that has taken root in society and difficult to stop, its resulting in large music stores becoming bankrupt and out of business. To deal with this the doubling of illegal music products must be stopped. Protection of duplicated music products (both $\mathrm{CD}$ and online music products) is still very controversial in many countries, because everyone can copy these music products easily [1]. Even the culture of buying CD is considered strange for people in Japan, Europe, and the United States. On the other hand, technology allows consumers to download songs, it become more preferred than go to music store to buy CD [2].

Changes in consumer behavior have a large impact on the decline in sales of CD. Nowadays, people prefer to download music through the internet and free music applications 
compared to buy $\mathrm{CD}$. The main reason is the ease of downloading music through the internet and music applications, and it is a new innovation in music products which can increase consumers' buying intention in music products and it can increase sales music product [3-5].

The development of technology can help companies to produce more creative, innovative music products which still need the right strategy to sell their products. Offering innovative music products through digital music and bundling, together with the selection of distribution channels through digital distribution, can attract consumers' buying interest in consuming music products $[3,5]$.

The right strategy for analyzing consumer behavior using 7P's marketing strategy (Product, Price, Place, Promotion, People, Physical Evidence, and Process) can influence consumer behavior and help companies to sell music products to the digital music market $[3,5,6]$. The music industry especially in Indonesia have to learn about consumers behavior in buying intention of music products to appropriate strategies and programs which can be formulated to take advantage of existing opportunities. Technology development is one of the opportunities that allows consumers to find information about good songs in the country and abroad. A comprehensive study of consumer behavior at national and international levels can provide useful input for the music industry to attract consumers towards music products.

The right marketing strategy is needed to attract consumers of music products that are legally offered by the company. The use of QFD can bridge and translate the wishes that consumers want into strategy that can made by a company. Company can use the strategy produce by QFD to find out the prioritize desires of consumers, to create and find new innovations towards those desires, then to improve existing conditions to achieve maximum effectiveness of marketing strategy. Companies can determine the formulation of the right marketing strategy by observing the purchase of consumer behavior towards music products. Based on the observations of consumers, it can be seen what things can make consumers interested in making purchases of music products legally. This research will be focused on consumers in Indonesia by observing the elements of marketing strategies and consumer's culture.

\section{Research Objectives}

Based on the issues raised, the purpose of this study is as follows:

1. To identify Consumer Requirements and Technical Requirements that are part of QFD analysis in purchasing music online in Indonesia. The study in analyzing consumer needs for online music purchase using 7P's marketing strategy.

2. To find out what attributes still require attention based on the QFD analysis that must be used and needs to be eliminated in the system design that will be developed for the purchase of online music according to user needs.

\section{Literature Review}

\subsection{Consumer Behavior}

Consumer behavior is centered for each person. In every human being certainly has different behavior, as well as behavior in making decisions. Consumer behavior can be influenced by various factors such as psychology, sociology, anthropology, and also economics, so it can be concluded that consumer behavior is a collection of all fields of science.

Consumer behavior is the actions of individuals who are directly involved in efforts to obtain, use, and determine products and services, including the decision-making process that precedes and follows these actions [7]. Consumer behavior is the study of how individuals, groups and organizations choose, buy, use, and use goods, services, ideas, or experiences to satisfy their needs and desires [8].

Based on the above explanation, it can be concluded that consumer behavior is a process where each individual determines their perceptions of a product or service, and various other thoughts such as experiences to satisfy all their needs and desires.

\subsection{Marketing Mix}

Marketing mix has an important role in influencing consumers to be able to buy a product or service offered by the company. The marketing mix elements consist of all variables that can be controlled by the company to satisfy consumers.

Marketing mix are elements of company organization which can be controlled by the company in communicating with guests and to satisfy guests [9]. Marketing mix is a good marketing tools which are set of products, pricing, promotion, distribution, combined to produce the desired response of the target market [10].

Based on definitions above, it can be concluded that the marketing mix is a good marketing tool in a company, where the company must be able to control it in order to influence the response of the target market.

\subsection{P's Marketing Strategy}

Marketing mix have a set of marketing tools known in $4 \mathrm{P}$ terms, namely product, price, place or distribution channel, and promotion, while in service marketing has several additional marketing tools such as people, physical evidence, and process, so it is known as 7P, it can be concluded that the service marketing mix is product, price, place, promotion, people, physical evidence, and process [10].

\subsubsection{Product}

Product includes planning and developing the right product or service to be marketed by changing existing products or services by adding and taking other actions that affect various products or services. 


\subsubsection{Price}

Price is a company management system that will determine the right base price for a product or service and must determine a strategy that involves price discounts, payment of freight costs and sharing of the variables concerned.

\subsubsection{Place}

Place (distribution), which is choosing and managing trade channels that are used to distribute products or services and also to serve target markets, as well as developing a distribution system for shipping and trading products physically.

\subsubsection{Promotion}

Promotion is an element used to notify and persuade markets about new products or services to the company through advertising, personal sales, sales promotions, or publications.

\subsubsection{People}

People are all actors who play an important role in the presentation of services so that they can influence the perception of buyers. Elements of people are employees of companies, consumers and other consumers. All employee attitudes and actions, employee dress and employee appearance have an influence on the success of service delivery.

\subsubsection{Physical Evidence}

People are all actors who play an important role in the presentation of services so that they can influence the perception of buyers. Elements of people are employees of companies, consumers and other consumers. All employee attitudes and actions, employee dress and employee appearance have an influence on the success of service delivery.

\subsubsection{Process}

Process is all actual procedures, mechanisms, and flow of activities used to deliver services. This process element means something to convey services. Processes in services are a major factor in the service marketing mix as service customers will be happy to feel the service delivery system as part of the service itself [10].

Based on these explanations regarding the marketing mix, it can be concluded that the marketing mix has elements that are very influential in sales because these elements can influence consumer interest in making purchasing decisions.

\subsection{Quality Function Deployment (QFD) Analysis}

QFD is a methodology in the process of designing and developing products that are able to integrate voice of costumers into the design process. In addition, QFD can also be used to design and develop a new product that can integrate quality into the design, meet the desires and needs of consumers (customer needs and wants) which are translated into technical requirements. In the process of product design and development, QFD is used at the evaluation stage of product concepts [11]. Definition of Quality Function Deployment (QFD) is a process of determining customer wants (what) and translating them into attributes (how) so that each functional area can understand and implement them [12]. Definition of QFD is a planning tool that is used to meet customer expectations [13]. QFD is an approach to product design, development, production, and in-depth evaluation of a product. QFD is a method used for planning and developing structured products that enable the development team to clearly determine the needs and desires of consumers, and evaluate each desired product or also the service capacity provided systematically to meet the wants and needs of consumers [14].

In general, QFD as a planning tool used to meet consumer voices in the form of desires (expectations) and needs of consumers. The main purpose of QFD is to involve users in the process of developing a product or service starting from the initial design of the product or service. It cannot be denied that customers will not be satisfied with a product, even if a product that has been produced perfectly, if they do not want or need it [15]. Therefore, the use of QFD can provide a large useful purpose for the company.

The main uses obtained from implementing QFD are [15]:

a. Focus on customers

QFD requires gathering input and feedback from customers. The information is then translated into a specific set of customer requirements.

b. Time efficiency

QFD can reduce product development time because it focuses on specific customer requirements and has been clearly identified.

c. Teamwork orientation

QFD is an approach to teamwork. All decisions in the process are based on consensus and are achieved through deep discretion and brainstorming. Because every action that needs to be done is identified as part of the process, so that in turn this encourages stronger teamwork.

d. Orientation to documentation

QFD produces comprehensive documents on all data relating to all existing processes and their comparison with customer requirements. This document changes constantly whenever new information is learned and old information is discarded. Up-to-date information about customer requirements and internal processes is very useful when there is turnover.

QFD can give the information about the voice of customers, and by using QFD, organizations can prioritize customer desires, find new innovations towards those desires, and can improve conditions so that maximum effectiveness can be achieved. Organizations can make process improvements by using QFD, so the organization can meet and exceed customer expectations. House of Quality is a matrix that is used in QFD, this matrix in the form of a house, used to describe the desires of the user / customer and the technical capabilities of the organization to design and produce goods or services according to the customer's 
wishes.

There are several ways you can use the QFD process. The ways that are often used in conducting QFD analyzes consist of 4 types [15]:

a. Affinity Diagram

An Affinity Diagram is a brainstorming method used to encourage creative thinking. This tool is very useful in helping to overcome all the obstacles that arise due to past failures.

b. Interrelationship Diagraph

Interrelationship Diagraph is used to explain causal relationships between various ideas recorded in the affinity diagram.

c. Tree Diagram

Affinity diagrams and linkages diagrams identify problems or problems and their interactions. The tree diagram to explain the tasks need to be done to resolve the problems faced.

d. Matrix diagram

It is a useful tool in identifying and graphically describing the relationship between responsibility, tasks, functions, and others. Matrix diagrams in Figure 1. Are often used to disseminate quality requirements into engineering characteristics and then into production requirements.

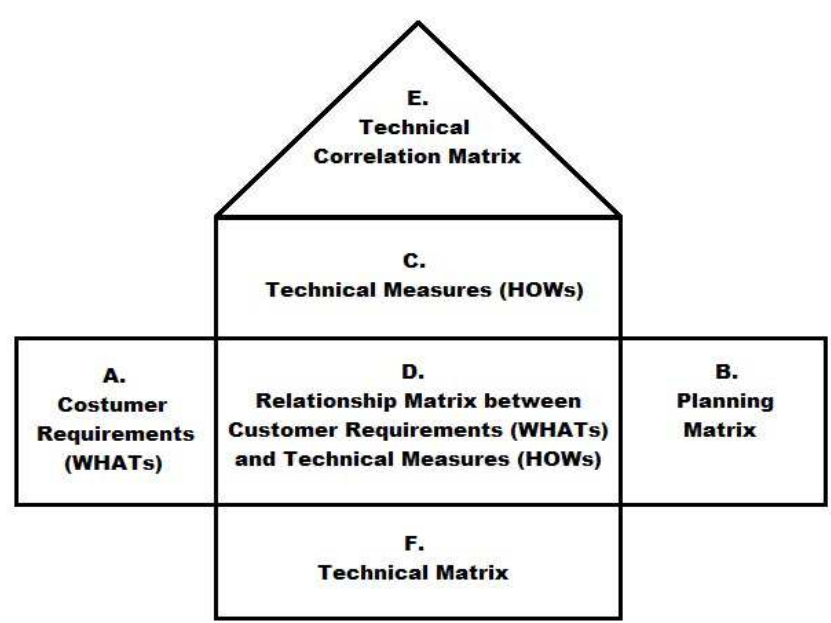

Figure 1. House of Quality [16].

QFD uses a matrix in the form of House of Quality in Figure 2, which is used to describe the needs and expectations of consumers and the company's technical ability to design and produce goods or services according to consumer desires.

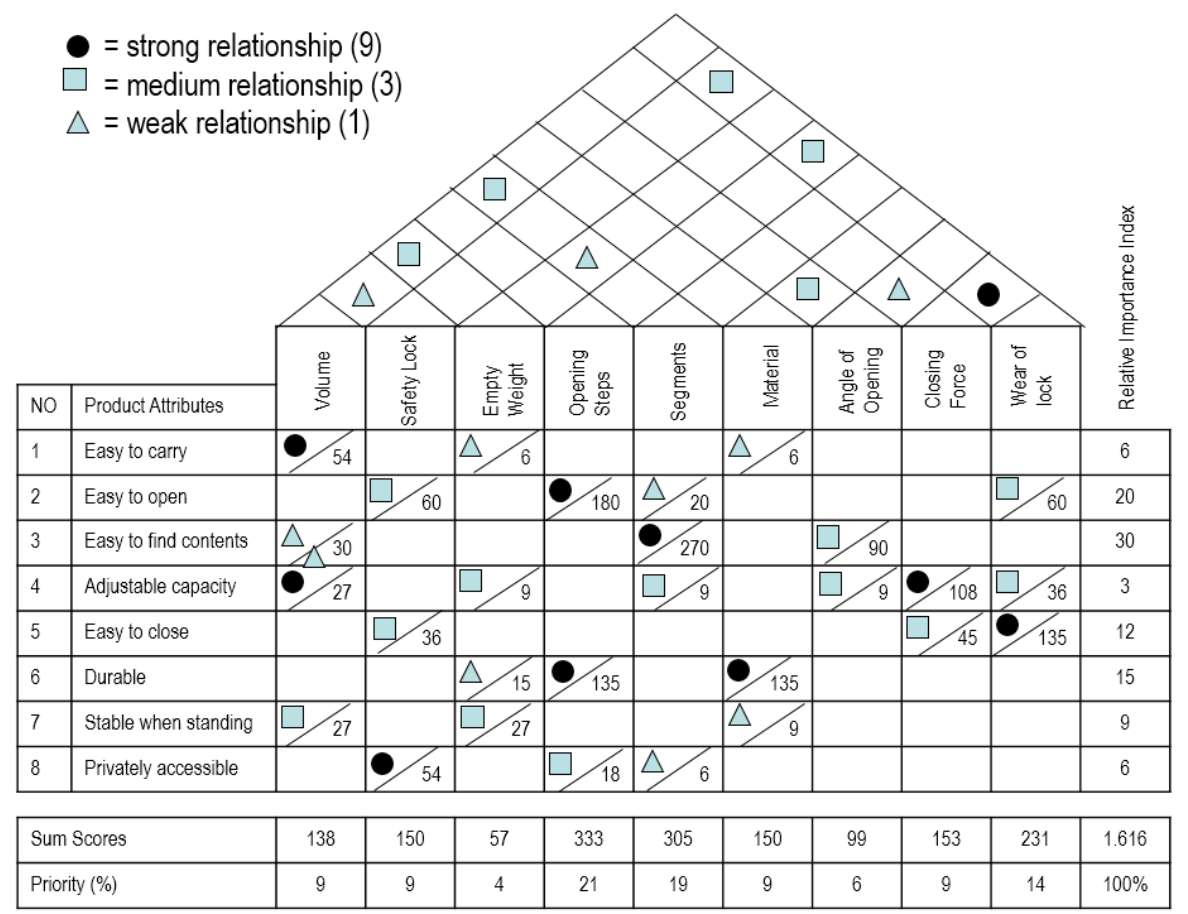

Figure 2. House of Quality [16].

\section{Method}

\subsection{Data Collection}

The first stage of research is collecting data through literature studies and field studies that will be used in conducting the questionnaire compilation process. Literature studies are conducted by looking for literature and journals related to research. Field studies on research material that will be examined by knowing the existence of a problem, so it can be formulated into research for a solution to the problem. Field studies are carried out by distributing questionnaires to online music users.

\subsubsection{Types and Data Sources}

This type of research used the quantitative descriptive research methods. Where the data source used is primary data. Primary data is obtained from answers of questionnaires 
obtained from online music users who have purchased music through smartphone or website applications.

\subsubsection{Population}

Population is a group of objects that have the same characteristics. The population in this study is consumer of online music in Indonesia. The population in this study are online music users who have purchased music through smartphone and website applications. The total population is 161 respondents spread throughout Indonesia.

\subsubsection{Sample}

Samples are part of the population, meaning that there will be no sample if there is no population. The author will use the Slovin formula in determining the number of samples. The formula was used because of the certainty of the population of online music users as a correspondent of 161 people spread throughout Indonesia.
Samples are a portion of the population that is intended to be carried out for research, data or results of this study are considered to have been representative of the population as a whole. The sample in this study is part of online music in Indonesia including http://joox.com, http://spotify.com, http://melon.co.id, and http://langitmusik.co. id

\subsubsection{Sampling Techniques}

The sampling technique used in this study was simple random sampling. The number of samples for this study was 161 respondents which sample size in the study was between 30 and 500 already represented [17]. Sampling is done using a questionnaire distributed to users of online music in Indonesia by simple random sampling. This research is to analyze the behavior of consumers in purchasing online music in Indonesia by implementing 7P's marketing strategy.

\subsection{Mapping 7P's Marketing Strategy}

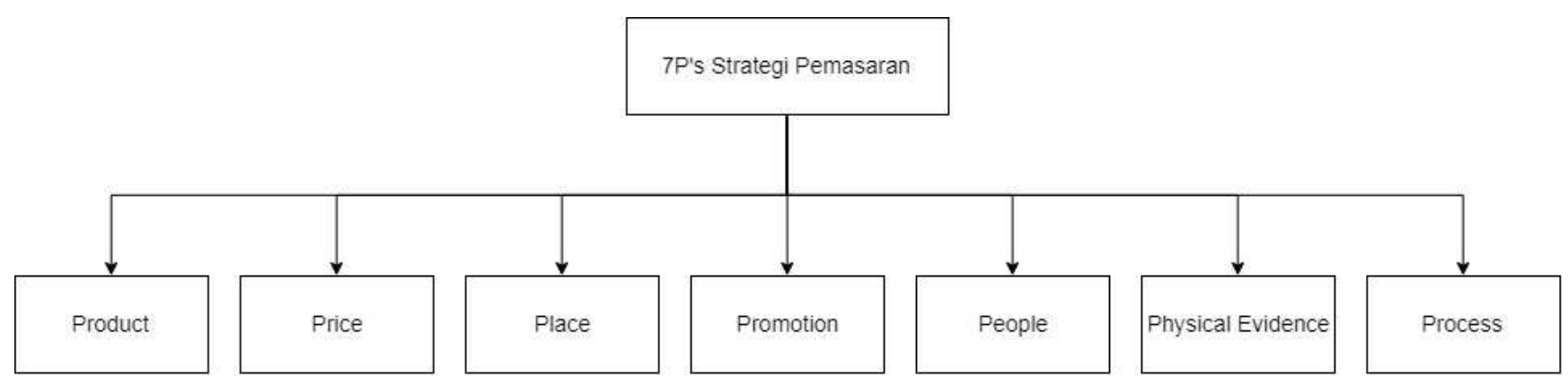

Figure 3. Mapping $7 P^{\prime}$ '

Product manages the planning and development of the right product or service to be marketed. Price determines the right base price for the product or service and must determine a strategy that involves price discounts, payments, etc. Promotion is an element used to notify and persuade markets about new products or services to the company through advertising, personal sales, sales promotions, or publications. People are all actors who play an important role in the presentation of services so that they can influence the perception of buyers. Physical Evidence is a real thing that also influences the consumer's decision to buy and use the product or service offered. Process is all actual procedures, mechanisms, and flow of activities used to deliver services.

\subsection{Quality Function Deployment (QFD) Analysis}

QFD is a methodology in the process of designing and developing products that are able to integrate voice of costumers into the design process. A process determines customer desires (what) and translates into attributes (how) so that each functional area can understand and implement it [12]. QFD is a planning plan used to meet customer expectations [14]. QFD is an approach to product design, development, production and in-depth evaluation of a product. The main focus of QFD is the involvement of consumers in the product or service development process as early as possible. The underlying philosophy is that customers will not be satisfied with a product, even if a product that has been produced perfectly, if they do not want or need it [15]. QFD translates what is needed by the customer into what is produced by the organization so as to enable the organization to prioritize customer needs, find innovative responses to those needs and improve the process to achieve maximum effectiveness. QFD uses a house shaped matrix which is often called House of Quality which is used to describe the desires of consumers and the company's technical ability to design and produce goods or services according to consumer desires.

\section{Discussion: Analysis of the Quality Function Deployment House of Quality}

Analysis of QFD with House of Quality has gone through the stages as described, namely the stage of determining product attributes by arranging product attributes based on priority (measured by giving importance weight) that reflects the things expected by consumers / product user.

Step 1: Product Attributes, arranging attributes in Table 1. 
Customer Requirements data obtained from the core questions contained in the questionnaire.

Table 1. Preparation of Product Attributes.

\begin{tabular}{l} 
Product Attributes \\
\hline Stable song quality \\
Packaging song files is not too big \\
Can choose and search songs by song, artist / band, type of music \\
Affordable online music prices \\
Easy in the process of buying and paying for online music \\
Advertising affects the sale of online music \\
Promotion affects buyer interest \\
Available song samples \\
Complete collection of songs, artists / bands, types of music \\
Various types of online music payment methods \\
Selection / request for songs is served quickly by the system \\
There is information about songs, artists / bands, types of music \\
The system provides music recommendations based on the music you like \\
Has features that are easy to use by consumers (user friendly) \\
Attractive graph display \\
Provide complete information to consumers \\
Good service to consumers \\
Have space to give opinions and rating \\
Have satisfaction if you buy and have music online \\
Attractive bundling offer \\
The product is practical to buy \\
Detailed and relevant information \\
\hline
\end{tabular}

\begin{tabular}{l}
\hline Product Attributes \\
\hline Consumers receive notifications via email \\
Relationship to social media \\
Easy to register \\
Easy and fast access \\
\hline
\end{tabular}

Step 2: Product Evaluation, this stage evaluates existing and / or made / modified products and compares them with competitor products (branch marketing process).

Step 3: Project Objective, for each product attribute, the target to be achieved is given an assessment (score) on a scale of $1-5$.

Improvement Rate is the target value or evaluation score; Improvement Rate for product attributes 1 (stable song quality) $=3 / 4=0.75$; product attributes 22 (consistency of screen display on each menu) $=5 / 2=2.5$.

Weight factors for attributes can be calculated using the following formulations: Weight $=$ Relative Importance Index $\mathrm{x}$ Improvement Rate For product attributes 1 - weight $=3 \mathrm{x}$ $1.25=3.75$ To calculate Wight $\%$ is $3.75 / 174.58 \times 100 \%=$ $2)$; the value of 174.58 is the total weight value.

Project Objective stage is done by paying attention to the performance of comparison data and relatives importance index (weight factor) of product attributes; there will be opportunities for improvements that can be made and set them as goals that must be met in the Project Design Modification project. The results of the three stages can be seen in Table 2 .

Table 2. Product Attributes, Product Evaluation (Branch Marketing Process).and Project Objective Stage.

\section{Stable song quality}

Packaging song files is not too big

Can choose and search songs by song, artist / band, type of music Affordable online music prices

Easy in the process of buying and paying for online music

Advertising affects the sale of online music

Promotion affects buyer interest

Available song samples

Complete collection of songs, artists / bands, types of music

Various types of online music payment methods

Selection / request for songs is served quickly by the system

There is information about songs, artists / bands, types of music

The system provides music recommendations based on the music you like

Has features that are easy to use by consumers (user friendly)

Attractive graph display

Provide complete information to consumers

Good service to consumers

Have space to give opinions and rating

Have satisfaction if you buy and have music online

Attractive bundling offer

The product is practical to buy

The consistency of the screen display on each menu

Structured and integrated links

Detailed and relevant information

Consumers receive notifications via email

Relationship to social media

Easy to register

Easy and fast access

\begin{tabular}{llllll} 
Ques-tion-naire & Tar- get & Imp. rate & RII & Wei-ght & Wei-ght (\%) \\
\hline 4 & 5 & 1.25 & 3 & 3.75 & 2 \\
4 & 5 & 1.25 & 2 & 2.50 & 1 \\
4 & 5 & 1.25 & 5 & 6.25 & 4 \\
4 & 5 & 1.25 & 2 & 2.50 & 1 \\
4 & 5 & 1.25 & 4 & 5.00 & 3 \\
4 & 5 & 1.25 & 3 & 3.75 & 2 \\
4 & 5 & 1.25 & 4 & 5.00 & 3 \\
4 & 5 & 1.25 & 4 & 5.00 & 3 \\
4 & 5 & 1.25 & 5 & 6.25 & 4 \\
4 & 5 & 1.25 & 5 & 6.25 & 4 \\
4 & 5 & 1.25 & 3 & 3.75 & 2 \\
4 & 5 & 1.25 & 4 & 5.00 & 3 \\
1 & 5 & 5.00 & 2 & 10.00 & 6 \\
1 & 5 & 5.00 & 5 & 25.00 & 14 \\
4 & 5 & 1.25 & 5 & 6.25 & 4 \\
3 & 5 & 1.67 & 4 & 6.67 & 4 \\
3 & 5 & 1.67 & 2 & 3.33 & 2 \\
1 & 5 & 5.00 & 1 & 5.00 & 3 \\
1 & 5 & 5.00 & 1 & 5.00 & 3 \\
3 & 5 & 1.67 & 1 & 1.67 & 1 \\
3 & 5 & 1.67 & 1 & 1.67 & 1 \\
2 & 5 & 2.50 & 5 & 12.50 & 7 \\
2 & 5 & 2.50 & 1 & 2.50 & 1 \\
1 & 5 & 5.00 & 5 & 25.00 & 14 \\
4 & 5 & 1.25 & 2 & 2.50 & 1 \\
2 & 5 & 2.50 & 1 & 2.50 & 1 \\
2 & 5 & 2.50 & 2 & 5.00 & 3 \\
4 & 5 & 1.25 & 4 & 5.00 & 3 \\
\hline
\end{tabular}


Step 4: Enter the Technical Requirements or Technical Parameters data, data on the technical requirements are answers to customer requirements as shown in Table 3.

Table 3. Making of Technical Requirements.

\begin{tabular}{l}
\hline Engineering Characteristics (Technical Parameters) \\
\hline Completeness of the contents of online music content \\
Attractive and interactive design display \\
Completeness of online music information \\
Accurate information \\
Information is easy to understand \\
Attractive graph display \\
Information has format accuracy \\
Navigation \\
Information search engine (Search Engine) \\
Search information based on keywords \\
Search information by artist / band \\
Search information by song title \\
Search information by type of music \\
Ranking based on search results \\
Song / artist / band / music type recommendations \\
Latest music / song information \\
The process speed displays the latest music \\
Easy to make payments for online music \\
Download process speed \\
Link to other related website addresses \\
Consumer satisfaction with online music \\
Promotion to attract consumers \\
The payment process is easy and safe \\
\hline
\end{tabular}

Step 5: Interaction Matrix, giving a correlation value between customer requirements and technical requirements. Correlation values are assessed from the strength of the relationship. Relationships like what happened: strong (strong), medium (medium), or weak (weak). By calculating the relationship score (the importance of the parameter attribute relation) $=$ the strength of relationship $\mathrm{x}$ weight of attribute.

For example: relationship score for attribute number 22 (consistency of screen display on each menu) and number of segments $=3 \times 7=21$. The number of scores for each technical parameter (per matrix column) will indicate the priority that must be taken from design improvement project.

Value priority can be obtained from: (some score / $\sum$ some score) x 100 .

Interaction Matrix which is the core of the QFD method. This stage is done by linking between product attributes and technical parameters. The relationship is then evaluated for each matrix cell, what kind of relationship is strong, medium (weak), or weak (weak). The results in the Interaction Matrix stage can be seen in Table 4. The purpose of QFD is to measure what variables need to be built because of the shortcomings in online music observed and the results of the QFD questionnaire where the user states the need is the value below 1. Based on the calculation of the Interaction Matrix stage, it can be seen that there are technical characteristics that have priority values below to be developed because of user needs.
Tabel 4. Engineering Characteristics.

\begin{tabular}{lll}
\hline Engineering Characteristics (Technical & Sum Scores & Priority (\%) \\
Parameters) & & \\
\hline Completeness of the contents of online & 52 & 3.21 \\
music content & 67 & 4.14 \\
Attractive and interactive design display & 67 & 12.23 \\
Completeness of online music information & 198 & 13.84 \\
Accurate information & 224 & 13.9 \\
Information is easy to understand & 225 & 3.77 \\
Attractive graph display & 61 & 14.52 \\
Information has format accuracy & 235 & 0.2 \\
Navigation & 3 & 2.04 \\
Information search engine (Search Engine) & 33 & 1.67 \\
Search information based on keywords & 27 & 1.67 \\
Search information by artist / band & 27 & 1.67 \\
Search information by song title & 27 & 1.67 \\
Search information by type of music & 27 & 0.1 \\
Ranking based on search results & 2 & 3.52 \\
Song / artist / band / music type & 57 & 12.8 \\
recommendations & 207 & 0.1 \\
Latest music / song information & 2 & 2.59 \\
The process speed displays the latest music & 27 \\
Easy to make payments for online music & 42 & 0.6 \\
Download process speed & 9 & 0.6 \\
Link to other related website addresses & 9 & 0.6 \\
Consumer satisfaction with online music & 9 & 2.1 \\
Promotion to attract consumers & 34 & \\
The payment process is easy and safe & 42 & \\
\hline & & \\
& & \\
\hline
\end{tabular}

Step 6: Interaction Between Parameters. Giving a correlation relationship between fellow technical requirements. Giving a relationship between these correlations is shown to know a technical requirement has a relationship or not with other technical requirements. Described as a roof at the House of Quality, Figure 4.

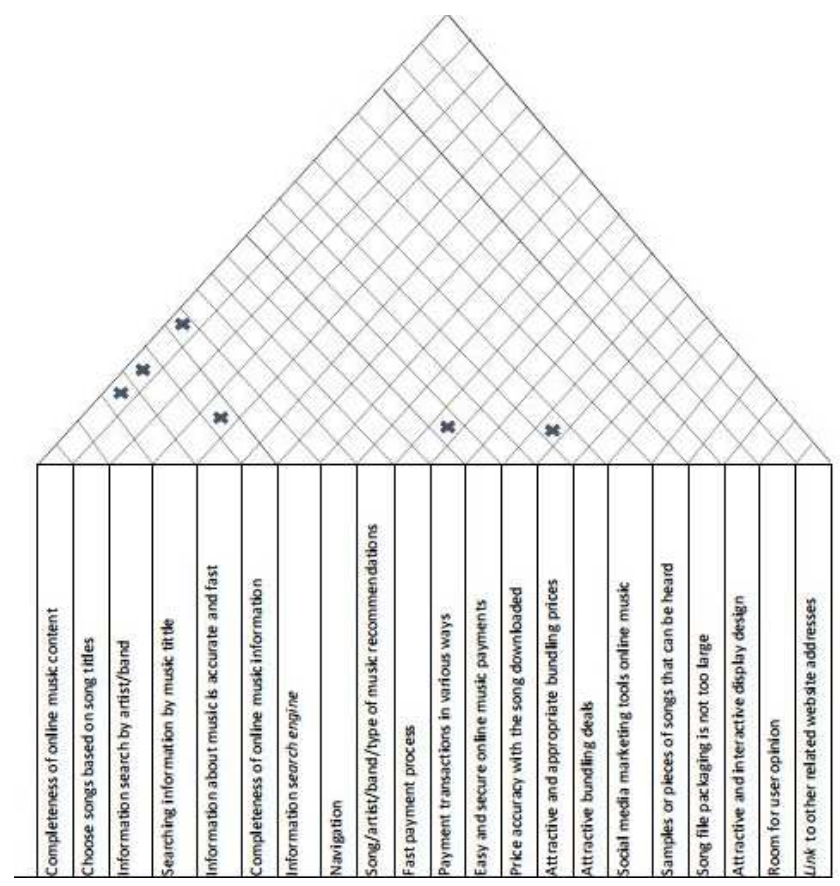

Figure 4. Interaction Between Parameters.

Step 7: Technical Analysis \& Target Values. Establish the 
values of technical parameters that need attention for improvement. This step 7 will provide:

a. Possibilities for improvement steps.

b. Determination of "target values" that must be met by the product design to be developed.

Determination is based on existing technical data and priorities of technical parameters that have been evaluated in accordance with step 5. From the calculation of the Interaction Matrix stage, it can be seen that there are technical characteristics that have priority values below 1 to develop:

Table 5. Engineering Characteristics that need to be developed.

\begin{tabular}{lll}
\hline $\begin{array}{l}\text { Engineering Characteristics (Technical } \\
\text { Parameters) }\end{array}$ & Sum Scores & Priority (\%) \\
\hline Navigation & 3 & 0.2 \\
Ranking based on search results & 2 & 0.1 \\
The process speed displays the latest music & 2 & 0.1 \\
Download process speed & 9 & 0.6 \\
Link to other related website addresses & 9 & 0.6 \\
Consumer satisfaction with online music & 9 & 0.6 \\
\hline
\end{tabular}

Priority values under 1 such as Table 5. are technical parameters that need to be developed. It needs to be developed in making music online because based on observations, users need these features when using online music, as an example is the download speed feature, users really need the process of downloading songs quickly without having to wait long. Another example is consumer satisfaction with online music, because there is still a lack of services and features or appearance in online music, causing users to still feel dissatisfied with using online music.

Step 8 . Feasibility. The improvements that will be carried out depend on:

a. Knowledge and skills of good workers from the design department.

b. Availability or absence of capacity for development

Step to 9. Development. Final result of QFD (Development Plan) decides the values for technical parameters and adjusts to the available development capacity. From the steps of drafting the House of Quality, it is concluded that the need to develop are navigation features, ranking based on search, speed of the process of displaying the latest music, speed of the download process, links to other related website addresses, and customer satisfaction with online music. After the steps are taken, House of Quality is formed in Figure 5.

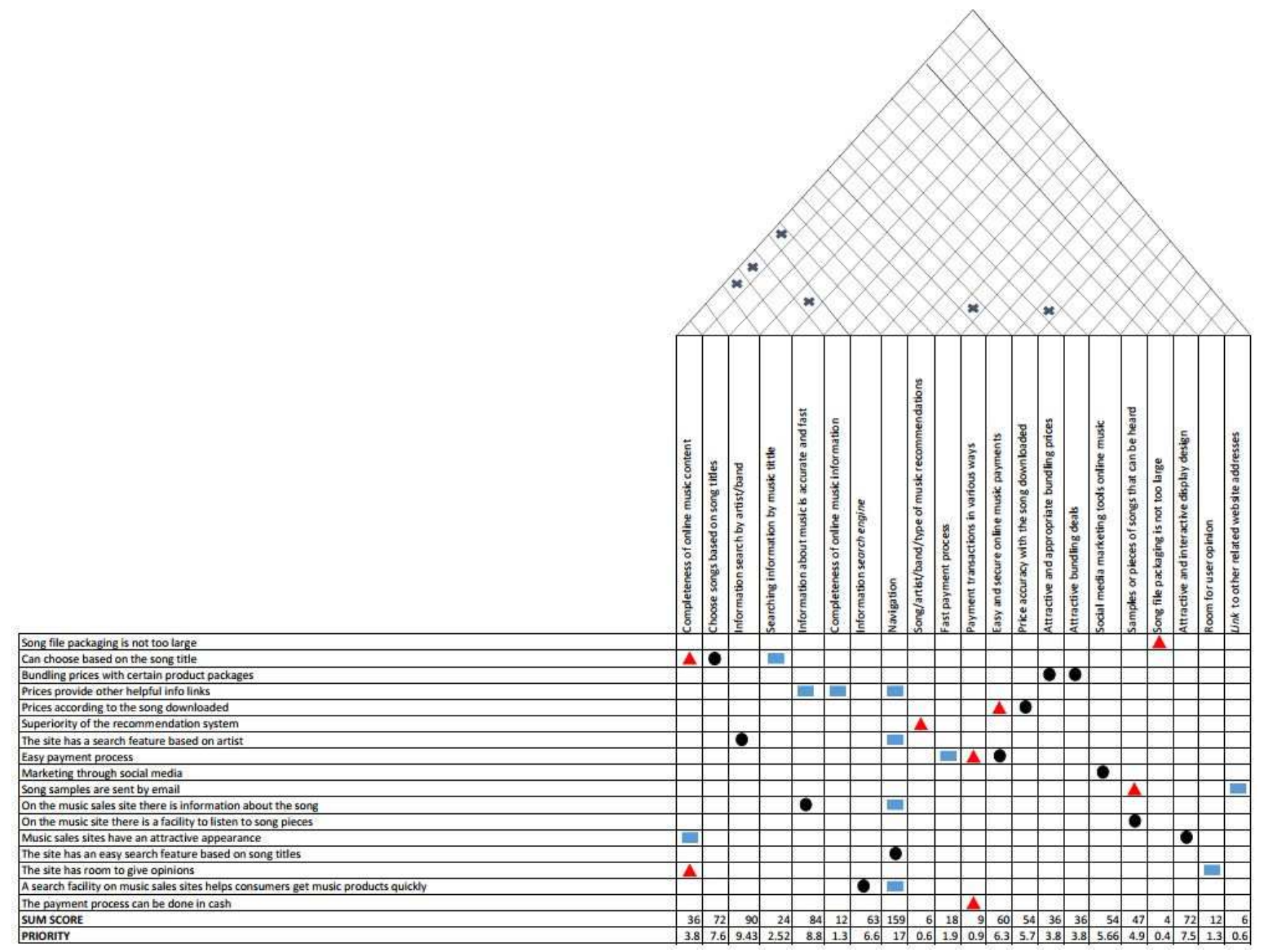

Figure 5. House of Quality. 


\section{Conclusions}

In this study an analysis of consumer behavior on purchasing online music in Indonesia has been carried out which can be used by system analysts in developing online music in Indonesia. Consumer behavior obtained through the distribution of questionnaires that have been made based on 7P's as the references assessed such as Product, Price, Place, Promotion, People, Physical Evidence, and Process.

The results of the analysis of data processing using QFD with House of Quality can be seen that there are 6 (six) technical parameters that have a value below 1 (one), it is indicating that the 6 parameters need to be developed in making a music online application. The technical parameters such as navigation, clear navigation will make it easier for users to use online music applications or software, so users with level of beginners and experts are easy to use online music applications. The results compilation from the House of Quality is concluded that it needs to be developed a navigation features, ranking based on search results, process speed, showing the latest music, process speed of download, links to other related website addresses, and customer satisfaction with online music.

\section{References}

[1] Cesareo, L., Pastore, A., 2014. Consumer's Attitude and Behavior towards Online Music Piracy and Subscriptionbased Services. Journal of Consumer Marketing, 31 (6/7), pp. 515-525. DOI: 10.1108/JCM-07-2014-1070.

[2] Saldana, Pablo. 2016. Differences in How Boomers and Millennials Expereince Listening to Recorded Music. Theses, Portland State University, Portland, USA. Doi: 10.15760/honors.309.

[3] Kusumawati, R. D., Oswari, T., Utomo, R. B., Kumar, V. 2014. The Influence of 7P's of Marketing Mix on Buying Intention of Music Product in Indonesia. Procedia Engineering, Vol. 97, pp. 1765-1771. https://doi.org/10.1016/j.proeng.2014.12.328.

[4] Kusumawati, Reni D., Purnamasari, D., Sardiyo. 2013. Innovation and Promotion Activities in the Internet to Increase Sales Volume of Music Product Using Augmented Reality. Egitania Sciencia Journal, 13 (7).
[5] Oswari, T., Kusumawati, RD., Yusnitasari, T., Shukla, V. K. 2018. The Affect of Marketing Mix and National Culture on Consumer Buying Intention of Music Product: A Case Study of Indonesia and India Consumers. Proceeding of International Conference on Management in Emerging Markets.

[6] Caillet, Maxence dan Daniel Yamba-Guimbi. 2010. The State of Digital Music Market in France and Its Tendencies. Dissertation in Business. Högskolan Halmstad, Perancis.

[7] Tjiptono, Fandy. 2001. Strategi Pemasaran. Edisi Kedua Cetakan Kelima. Andi Offset, Yogyakarta.

[8] Kotler, Philip and Keller, K. Lane. 2016. Marketing Management. 15th Edition, Prentice Hall, Inc. A Pearson Education Company, Upper Saddle River, New Jersey.

[9] Zeithaml, V. A. Bitner, M. O., dan Gremler, D. E. 2013. Service Marketing: Integrating Customer Focus Across The Firm, 16th Edition. McGraw-Hill/Irwin, New York, NY.

[10] Kotler, Philip and Gary Armstrong. 2018. Principles of Marketing, 17h Edition, Prentice Hall, Inc. A Pearson Education Company, Upper Saddle River, New Jersey.

[11] Domingos, A., Silva, J. C. M., Pereira, J. A. 2017. On The Use of The Quality Function Deployment Matrix for Flexible and Quantitative Prioritization. Journal of Advanced Management Science, Vol. 5 No. 5.

[12] Heizer, J. and Render, B. 2005. Operation Management, 7th Edition, Prentice Hall, New Jersey.

[13] Chen, L. and Chen, C. 2014. Normalisation Models for Prioritising Design Requirements for Quality Function Deployment Processes. International Journal Prod. Res., Vol. 52 No. 2, pp. 299-313.

[14] Cohen, Louis. 1995. Quality Function Deployment: How to Make QFD Work for You. Prentice Hall, New Jersey.

[15] Tjiptono, Fandy \& Anastasia Diana. 2003. Total quality management, Andi, Yogyakarta.

[16] Alrabghi, Leenah O. 2013. QFD In Software Engineering. Master Thesis, Kent State University.

[17] Sugiyono. 2012. Memahami Penelitian Kualitatif. Bandung: ALFABETA. 